Article

\title{
Platform Urbanism: Technocapitalist Production of Private and Public Spaces
}

\author{
Sybille Bauriedl ${ }^{1, *}$ and Anke Strüver ${ }^{2}$ \\ ${ }^{1}$ Department of Geography, Europe-University Flensburg, 24943 Flensburg, Germany; \\ E-Mail: sybille.bauriedl@uni-flensburg.de \\ 2 Department of Geography and Regional Science, University of Graz, 8010 Graz, Austria; E-Mail: anke.struever@uni-graz.at \\ * Corresponding author
}

Submitted: 30 June 2020 | Accepted: 2 September 2020 | Published: 15 December 2020

\begin{abstract}
Digital technologies and services are increasingly used to meet a wide range of urban challenges. These developments bear the risk that the urban digital transformation will exacerbate already existing socio-spatial inequalities. Graham's assumption from nearly 20 years ago (2002) - that European cities are characterised by various forms of socio-spatial segregation, which will not be overcome by digital infrastructures - thus needs to be seriously acknowledged. This contribution critically scrutinizes the dominant narratives and materializations of standardised smart urbanism in Europe. We investigate how the prospects of improved efficiency, availability, accessibility and quality of life through digital technologies and networks take the demands and effects of the gendered division of labour into account. By zooming in on platform urbanism and examples related to mobility and care infrastructures, we discuss whether and to what extent digital technologies and services address the everyday needs of all people and in the same way or whether there are exclusionary lines. Our objective is to bring digital and feminist geographies into dialogue, to stress the mutual construction of society and space by platform economies and to ask how gendered geographies in cities are produced through and by digitalisation.
\end{abstract}

\section{Keywords}

care; digital divide; digital technologies; gender; mobility; platform urbanism; public-private; smart city; socio-spatial

\section{Issue}

This article is part of the issue "Digital Geographies and the City" edited by Wen Lin (Newcastle University, UK).

(C) 2020 by the authors; licensee Cogitatio (Lisbon, Portugal). This article is licensed under a Creative Commons Attribution 4.0 International License (CC BY).

\section{Introduction}

The increasing platformisation of everyday life has recently become a subject of research among social sciences. Sociologists use the term "platform society" (van Dijck, Poell, \& De Waal, 2018) to describe a society characterized by the use of platforms through which information, goods and services are exchanged and in which platforms influence private and public life via data flows and algorithms. With the platformisation of more and more life spheres, the public's interest in ensuring both the accessibility of information and services and the democratic control of data have taken on a new significance as private corporations, governments and civil society compete for control over these interests. Critical urban studies use the concept of 'platform urbanism' to examine the significance of these changed everyday practices and power shifts brought about by the expansion of platform operators into all areas of urban life (Barns, 2019, 2020; Graham, 2020; Richardson, 2020). In this article we take the everyday as point of departure to look at how platforms connect services and consumers: How gendered norms in urban everyday life are re-produced by the platformisation of services, especially by mobility and care-work platforms. These two sectors appear to be particularly well suited for our argument, since platformmediated services in these sectors have recently gained importance and are designed by international platform 
companies. In general, cities are expected to bring forward sustainable solutions to tackle both the care crisis and the mobility crisis through the digitisation of services. For analytical reasons, we find it particularly interesting to put the platform dynamics of these two sectors in relation to each other, since they serve supply needs in both public space (urban mobility) and private space (home care), and thus achieve different visibilities and modes of regulation.

To date, there exist ample research on the dynamics of platform urbanism in North American cities (Elwood, 2020; Leszczynski, 2020). Research on both mobility platforms and care platforms has tended to focus on the North American urban context, although the latter also includes Asian, Australian and African cities (Flanagan, 2019; Hunt \& Machingura, 2016; Kong \& Woods, 2018; Strauss \& Xu, 2018). By contrast, European cities are underrepresented in studies on platform urbanism, even if we know that "digitality is deeply implicated in socialspatial processes of exclusion" (Elwood, 2020, p. 1) and European cities show specific socialspatial processes and a specific demand for platform services due to their urban landscape, population structure, mobility culture and gendered division of labour. With this contribution, we will stress the regionally specific dynamics of platform urbanism.

Pairing the perspective on platformisation with smart city discourses and integrating them into a discussion of social aspects of platform urbanism, we ask how 'smartness' and the production of normative knowledge through datafication, platformisation and algorithms shape urban everyday life. We rely on approaches rooted in feminist digital geography, as they open up a view of diverse scales of urbanization, relate everyday practices to public and private spaces, and examine the production of socio-spatial difference and inequalities. We consider it essential to address how urban platforms produce embodiments, subjectivities, normative frames of social and spatial interactions, and gender norms to understand the social implications and variations of digital divides.

In general, feminist digital geographies are concerned with both epistemological and ontological approaches to datafied bodies, subjectivities and spaces in everyday life. They extend feminist critiques of 'objective science,' for example those that address how digital algorithms manifest socio-spatial inequalities. Scholars who address "digital practices as social praxis" (Elwood \& Leszczynski, 2018, p. 630) have looked specifically at how digital technologies transform or re-produce gender relations (for example, the gendered division of labour in general and digitally mediated work in particular). In this context, Richardson (2018) put forward a feminist perspective on digital technologies and their impact on the geographies of work, relying on established feminist approaches to emotional labour, embodied work, and care-work at home-that is, an approach that viewed social reproduction and its socio-spatio- temporal relations as comparable to paid work outside the home.

With respect to smart cities, feminist digital geographies have criticized the framing of social urban problems as ones that can be solved through technological solutions-for example by setting up sensor technologies that regulate traffic instead of biking and walking lanes (see Elwood, 2020; Elwood \& Leszczynski, 2018). However, intersectional analyses of the digitally mediated aspects of urban everyday life-that is, studies that explore how digital technologies are enmeshed with gendered, classed, racialised socio-spatial relations and how digital practices shape socio-spatial everyday praxes of different bodies and subjectivities-are still scarce. Following the observation that "most urgently, the 'digital' requires attention to the space and time of everyday life in order to attend to the ways the co-production of space, people, and the digital coalesce" (Gieseking, 2019, p. 87), this article draws on two of the main themes of feminist digital geographies as springboards to discuss everyday platform urbanism and gendered digital divides. These themes-work/caring and mobility/sharing - both refer to and depend on everyday activities. Moreover, both have been established within pre-digital feminist geographies against the background of the gendered division of labour and the spatialisation of gendered labour. The spatialisation of this division illustrates the mutual construction of society and space (Massey, 1994, 2005) and of gender and home, respectively: The division of labour both affects and is itself an effect of the spatial separation of 'male' productive work in public spaces and 'female' reproduction work at home/private spaces (Brickell, 2012). Moreover, as Massey argued more than two decades ago, "spaces and places are not only themselves gendered, but in their being so, they both reflect and affect the ways in which gender is constructed and understood" (Massey, 1994, p. 179). The mutual construction of society and space needs new attention in connection with digitalised everyday life in urban societies and spaces, but we especially lack critical investigations of platform capitalism in smart cities. Attoh, Wells, and Cullen (2019), for example, discuss labour with reference to the production of data for exploitation by intermediating platforms, such as Google. Only in a second step do they refer to the everyday life of the workers and consumers who produce this data via platforms. Relying on recent literature, this article addresses the latter group, focusing especially on care workers who use peer-to-peer platforms and on car sharing offered via business-to-consumer platforms, relying on recent literature.

The starting point of this contribution is a critical scrutiny of the dominant smart city narratives with respect to their promises for sustainable urban development and the contradictions those promises bring forth. Following this, we discuss the concrete consequences of digitisation for the socio-technical relationships between citizens, cities, and urban infrastructures with reference 
to platform urbanism. By exploring two central sectors of urban everyday life-care-work and mobility-we illustrate how platform economies and platform practices increasingly standardise the demand for these services, (de)privilege urban spaces, and manifest the gendered division of labour. In large European cities, demand in these sectors is increasingly organised through platforms, and the same platform companies are active in most major European cities (e.g., ShareNow in the mobility sector, care.com in the care sector). Against this background, we investigate whether and to what extent digital technologies and services address and treat all people equally, or whether there are socio-spatial regimes at work that include and exclude certain categories of individuals along gender lines (and their intersections with class and race). In our conclusion, we take a systematic look at the explicit role of and production of space in interconnection with the socio-technological changes that sectoral platforms bring about, and also seek to bring digital feminist geography into a dialogue with critical urban studies.

\section{Smart City Narratives}

This is the vision of the European Commission's programme for a European innovation partnership on smart cities and communities:

A smart city is a place where traditional networks and services are made more efficient with the use of digital and telecommunication technologies for the benefit of its inhabitants and business. A smart city goes beyond the use of information and communication technologies for better resource use and less emissions. It means smarter urban transport networks...a more interactive and responsive city administration, safer public spaces and meeting the needs of an ageing population. (European Commission, 2020)

Smart city narratives like that represented in the above citation always aim to tell a story of innovation or progress. They have a strong reference to 'sustainability' and a vision of a world in which people, the economy and the environment can happily and lovingly interact in mutually supportive, cohesive, and historically reproducible ways, mediated by increasingly 'smart' technologies (Swyngedouw \& Kaika, 2014; Wiig, 2016)-even if the corresponding visions of progress differ fundamentally from the principles of a pollution-free, healthy city or a social housing policy.

Idealization of the 'smart city' is based on the view that such cities improve the quality of life for all by increasing the flexibility, diversity, and accessibility of nearly all local services, such as those related to mobility and energy supply, online shopping, urban navigation, environmental monitoring, public wifi, e-governance. These promises are always connected to a universalized idea of independence and freedom, with scant attention paid to the fact that these promises and ideals are not equally valid and attainable for all people. The aims associated with flexible services, and the need for them, have different meanings and relevance for different social groups, in accordance with the gender, class, race, sexual identities, age and body ability of each. Promises, images and visualizations of smart city technologies reinforce rather than disrupt traditional gendered associations and replicate existing network capital inequalities (Wigley \& Rose, 2020).

However, gender normativity is not produced by technology as such, but by the digital services of information and communication technology companies. Digitalised urban infrastructures and supply services do not automatically meet all the needs and accessibility options of all individuals. Digital divides emerge between generations with different levels of digital literacy and between persons in different income groups, some of whom cannot afford Internet-enabled smartphones and digitalised services or lack the requisite credit cards, residency status, or other formal requirements.

'Smart city' is thus not a single narrative, but rather builds on polyphonic and contested narratives with correspondingly different imaginary representations for present and future cities (see Bauriedl \& Strüver, 2018). Recent years have witnessed the rapid rise of extensive debates within critical urban studies on digital urban transformation on the subjects of smart cities, smart urbanism, and platform urbanism, defining and differentiating these concepts in different ways (Lee, Mackenzie, Smith, \& Box, 2020). In this article, we consider 'smart city' solely as discourse and programmatic urban policy, since there are no explicit criteria for smart cities (Bauriedl \& Strüver, 2018). In analysing the resultant forms of urban praxis, we understand the digital transformation of urban everyday life as a form of smart urbanism. In the next section, we address platform urbanism as a specific practice of smart urbanism, one characterized by platform economies and the manifold use of intermediate platforms. Promoting a debate that deconstructs this universal smart city storytelling requires, first of all, our sensitivity to the "diverse histories, cultures and political economies and variegated forms of capitalism that shape patterns of urban and economic development and the relationship between state, market and society" (Kitchin, 2015, p. 133). We investigate how the prospects of improved efficiency, availability, accessibility and quality of life through digital technologies and networks take into account the demands and effects of the gendered division of labour.

\section{Platform Urbanism}

European cities are characterised by multiple forms of spatial segregation and social polarisation, which are not automatically remedied by digital infrastructures (Gilbert, 2010; Graham, 2002). Far from being helped by digitalisation, social marginalisation is actually inten- 
sified by the creation of new jobs in the urban platform economy, known as the 'gig economy,' with its precarious employment conditions (Wiig, 2016). In what follows, we discuss cities as datafied space (Kitchin, 2014) in which digital data in general, and platform economies in particular, increasingly shape and intermediate urban life.

As the evolution of platforms indicates "the sociotechnical relationships between citizens and cities," we need to ask how "platforms are changing urban sociospatial practices and services" (Lee et al., 2020, p. 116). This is increasingly addressed as 'platform pivot' and 'platform urbanism' - as the manifestation of smart city narrations, and as digitally enacted everyday urbanism as it enters and shapes socio-spatial experiences and daily urban lives, beyond the scope of city halls and public discourses (Barns, 2019).

As socio-technical ties between cities, companies and citizens, platforms are based on the relational dynamics between code, commerce and corporealities in technology-driven everyday life. They change both how cities themselves function, and how people live, work, eat, communicate and move in cities (Barns, 2019; Lee et al., 2020). Against this background, we adopt the following differentiation of smart and platform urbanism:

Smart urbanism is primarily about optimizing oversight of city systems through state procured, corporate provided 'solutions,' whereas platform urbanism aims to transform and/or take over the operations of city services that tend to be more market- or consumer-oriented. These two models do not necessarily supersede or even compete with each other; rather, they work simultaneously in different spaces. (Sadowski, 2020, p. 2)

Because of this shift towards daily life, platform urbanism seems easier to access empirically than 'smart city' strategies and their related meta-narratives of neoliberal capitalism. However, the city is not a spatial container, and replacing platform capitalism with platform urbanism is a grossly oversimplified solution (Graham, 2020). In her feminist theoretisation of platform urbanism, Leszczynski (2020) stresses the need to go beyond urban platforms as part of neoliberal capitalism and instead to focus on the everyday, thereby exploring the emancipative potentials of urban platforms. In the same vein, Elwood (2020) emphasises the task of critical platform research in reconstructing normative digital-socialspatial relations of technocapitalist urban life. In this context, technocapitalism is understood as the capitalism that is associated with the emergence of new technology sectors, the corporative power, and new forms of organising spatial and social relations:

Platforms benefit from the population density and spatial proximity of users/workers in cities. There are more opportunities for mediating social relations and extracting economic value in large, diverse markets. There is a pool of precarious 'freelancers' who are shuffled from gig to gig. (Sadowski, 2020, p. 3)

Urban platform economies change the consumption, perception and production of material urban space. However, this change is not only economically driven, but also practiced by citizens who shape urban structures from their smartphones. This is particularly obvious regarding (on-demand) digitally mediated service platforms, to which we will now turn.

\section{Gendered Platform-Mediated Services: Sharing and Caring in Urban Daily Practices}

The gendered division of labour has been criticised by feminist urban planners, social geographers, and others since the 1970s (see, e.g., Bondi, 1998; Bondi \& Rose, 2003; Brickell, 2012; Massey, 1994; Meehan \& Strauss, 2015). This critique encompasses the different symbolic as well as monetary values of paid work outside the home-associated with men or masculinity-and private domestic (physical and psychosocial) reproductive work, which has female connotations and is predominantly done by women. Accordingly, gender norms and stereotypes of femininity and masculinity play important roles in the division of labour, in addition to broader socio-economic structures. The critique also bears a direct reference to the urban planning model of functional separation that prevailed during the 1960s/1970s, which spatially isolated living, working, shopping and other activities from each other in order to prevent possible negative influences. In tandem with the trend towards suburbanisation since the 1960s, residential areas have been increasingly built at the margins of the city; as a result, the gendered division of labour is linked to a spatial division, marginalising care-work at home, both socially and spatially. The spatial manifestation of the gendered division of labour thus includes the idea and ideal of the home as a place for women to do careand housework that is unpaid, often hidden or literally overlooked and invisible (Bondi, 1998; Hayden, 1983). Moreover, the gendered division of labour and its sociospatial organisation cannot be approached through gendered identities, but only through questions of the organisation of work in capitalist structures (Parker, 2011).

In this article, we examine different service platforms of general interest to advance the debate: free floating car sharing mobility and home care. For more than a decade, services in these two sectors have been mediated between business to customer and between peers via platforms that create new opportunities to use public and private spaces differently.

\subsection{Digitally Mediated Mobility Services: Car Sharing}

Everyday mobility practices in cities are very diverse: transportation users may travel alone, as a family, or in 
a group; they can be young or old, athletic or physically challenged, have abundant or very little money, have or lack the ability to cycle and drive, be scared or courageous. In going from one place to another, these consumers may cover short distances or long distances, and may or may not use a chain of transportation options. All these mobility conditions and needs, together with the built transport infrastructure and the available modes of transport, are crucial to each person's mobility decision. The demand for flexibility and accessibility and the costs of urban transport services result from all these very different structural conditions and individual needs.

The mobility debate is largely characterised by statements about the positive potential of technological innovations (Liyanage, Dia, Abduljabbar, \& Bagloee, 2019). In recent years, the near-ubiquity of Internet in cities and the spread of mobile end-user devices has injected a new dynamism into urban mobility offers and services. In particular, an expanding range of car sharing services is now considered to be a characteristic of smart cities. In addition to the use of private vehicles and public transport, a variety of platform-mediated sharing options (car sharing, bike sharing, scooter sharing, ridehailing, ridepooling) are available. Car sharing involves the sharing of private vehicles and transport services via Internet platforms, using various forms of mediation (peer-to-peer or peer-to-pool), location ties (stationary or floating) and various types of vehicle use (self-driving, passenger or autonomous driving; Prettenthaler \& Steininger, 1999). These platforms give consumers connected, real-time information to help optimise their use of private and public transport (mobility as a service).

Given that (urban) mobility is gendered and thus produces socio-spatial inequalities (Law, 1999), one issue of central relevance to future mobility infrastructures is whether new smart mobility services address all transport users, or rather prioritise already privileged groups and thus reproduce urban inequalities. In the following section, we focus on the potential of car sharing services to promote a socially just urban development (Sheller, 2012), examining whether such services can create typical route chains for caregiving activities. Traveling from one stop to another is a daily routine for unpaid caregivers (Uteng \& Cresswell, 2008). These reproductive activities are still largely viewed as women's work. In order to discuss the available mobility potentials, we now take a closer look at the offers and business models put forth by car sharing platforms.

Emerging in the late 1980s in Switzerland and Germany, car sharing initially surfaced in the form of small projects created by environmentally minded groups. Internet applications have made booking procedures more efficient and user-friendly, while smart cards and later smart locks improved access to cars. Germany is clearly the regional focus of free floating car sharing within Europe in terms of the number of mobility services and the size of vehicle fleets. The market for free floating car sharing providers is currently dominated by the ShareNow-platform (a joint venture of car2go operated by Daimler and DriveNow operated by BMW). According to information provided by the companies themselves, by 15 May 2020, ShareNow had approximately 14,000 vehicles in use in eight European countries (ShareNow GmbH, 2020). Daimler started this business model in 2008 with its car2go platform, Europe's first business to customer free floating car sharing operation, which mainly served Germany's largest cities. Today's car sharing organisations can be classified into five main types of business models, based on their operational characteristics and business model variables: 1) free-floating within an operational area, 2) free-floating with pool stations, 3) round-trip and home-zone based, 4) round-trip and station-based, and 5) peer-to-peer. All platform providers repeatedly use the keywords 'increased resource efficiency' (producing and sharing fewer vehicles), 'flexibility' (permanent access to means of transport that meet demand), 'optimisation' (increased traffic flow) and 'acceleration' (information on the fastest connections).

All of the platforms provided by automotive companies follow the one-way model of mobility, which offers high flexibility in that it allows users to drop off a car anywhere within a designated city area (freefloating). By contrast, it offers limited flexibility in terms of scope, since the business areas of the mobility platform providers are limited to inner city areas and the cost structure of free floating car sharing supports one-way mobility. The business model of smart mobility platforms adapts other offers to users' movement profiles. This leads to a self-reinforcing process that works to privilege specific social groups and urban identities and creates a gendered digital gap (Alonso-Almeida, 2019, p. 38; Strüver \& Bauriedl, 2020).

In many mobility studies, the description of mobility as a complex physical and social relationship is reduced to measurable figures and calculable flows of goods and people (Hanson, 2010, p. 13). The few available studies on the social composition of users of smart mobility services deliver very limited findings on the correlation of user interests and social categories. Mobility studies tend to use a quantitative approach that is based on movement data or mass surveys. Nevertheless, one trend on gender relations can be identified: In European cities men are the main users of stationary carsharing, for which average user age is higher than for free floating car sharing (Uteng \& Cresswell, 2008). In German cities-where carsharing is most widespread-up to $80 \%$ of free floating car sharing users are male, well-educated and in full-time employment (Giesel \& Nobis, 2016). Karen Lucas (2012, p. 107) has coined the term "transport poverty" to describe the link between social exclusion and mobility. Along the exclusion dimensions, various forms of mobility-related disadvantage (e.g., lack of information about mobility opportunities or high transport costs) overlap with aspects of social disadvantage (e.g., low income or poor health). 
It is not the intention of smart mobility to be gendersmart (Singh, 2019). Current feminist mobility research focuses predominantly on the political when looking at issues such as transport system configuration, resource allocation, priority setting, and transport system user construction. They criticise the liberal paradigm for transportation planning, which assumes individual rationality and a market-oriented economy while neglecting the structural conditions of mobility behaviour and mobility preferences (cf. Scholten \& Joelsson, 2019, p. 7). In cities, women travel on average fewer passenger-kilometres, but often have a higher total driving time than men, with many stops related to paid work as well as care-work and housekeeping. They often create complex chains of multi-destination routes within a smaller mobility radius.

\subsection{Platform-Mediated Care-Work}

While the mutual constitution of gender and space is multi-scalar, in the case of care-work it is focused on the micro-level of the household. For most people, the home is an essential part and place of everyday life, a place for regeneration and reproduction, but also where gender norms are negotiated (Beebeejaun, 2017; Bondi \& Rose, 2003; Peake, 2016). The sharp increase in the proportion of women working in paid jobs outside the home has transformed the gendered division of labour and its spatial manifestations discussed above. Since the 1990s, some of the duties associated with traditional reproductive work have been outsourced to other persons/spaces (for example, by using a delivery service or eating out instead of shopping and cooking, or to digital assistants such as cleaning and care robots). The growing commodification of care-work has made this type of work more public and more visible, but not necessarily more recognized. At the same time, the privatisation of social services and healthcare reforms by neoliberal restructuring and the consequences of the global financial crisis have re-integrated some reproductive work into the home along gender norms. Reproductive services and carework thus have been 'privatised' again -in the sense that they have returned to private homes and, for example, are being provided as unpaid, home-based care by relatives (Federici, 2019; Huws, 2019). Moreover, neoliberal restructuring particularly affects women in low-income households and with precarious jobs. Against this background, Beebeejaun (2017) has reconsidered the gendered division of labour and the gendered separation of public and private places in neoliberal cities and points out that gendered everyday life in urban contexts remains underexplored (see also Gilbert, 2010; Peake, 2016; Strauss \& Xu, 2018). Yet, gender (and class and race) are organising principles of societies, and thus preceded the experiences of individual subjects. Gender continues to shape urban forms, functions and spatial structures, e.g., the separation of urban functions related to home and work-which, in turn, shape gender norms and subjectivities.
Care-work in the private sphere of the home illustrates-in addition to the neoliberal policies and politics of reproducing gender relations - the growing differences (and dependencies) between women of the professional classes and unskilled working-class women. The mounting demand for paid care-work such as childcare, eldercare and domestic services, including the commodification of routine domestic tasks such as cooking and cleaning, reflects a situation in which women working in professional occupations often depend on the care-work of other women (and sometimes men; Meehan \& Strauss, 2015). In concentrating on paid care services in the home, Dyck (2005) has stressed the intersections of gender, class, race and ethnicity on the one hand, and the complicated interconnections between neoliberalism, globalization and changing age structures on the other. Low-paid care-jobs within homes soften the impact of public sector privatization and especially of cuts to welfare programmes and public childcare and health care. This is but one of many arguments that call into evidence the major significance of the spaces of everyday life in general, and the private sphere of home in particular, to research on urban platform economies. Moreover, this is a refinement of Gilbert's (2010) assertion that race, gender and technocapitalism are intertwined as inequalities in urban spaces. She stresses the need to research in depth people's daily lives and their experiences of gender, race and class as part of the relations of digital and urban inequalities that affect labour markets and vice versa.

Care-work platforms are typical examples for socalled lean platforms of the gig economy (Srnicek, 2016). Unlike mobility-platforms, they are demanddriven and set up as peer-to-peer-platforms that match care-workers and households by means of registration fees or transaction fees for the workers. Taking into consideration that the previous global commodification of care-work at the turn of the millennium was interrupted by the financial crisis in $2007 / 2008$, such platforms have accelerated the recommodification of care-work. On the one hand, the recommodification can be seen as a result of the crisis, since formerly public care services were privatised after 2008 as part of neoliberal restructuring (Huws, 2019). On the other hand, digital platforms providing care-work also have their roots in this crisis, since setting up platforms was and is not dependent on large capital investments but rather on existing 'assets' such as cars, flats, working bodies to be 'shared' between service providers and consumers:

This post-crash landscape has also provided the perfect conditions for new flows of (venture) capital in the form of digital platforms that want to operate core services related to how we live, how we work, how we travel, how we consume. (Sadowski, 2020, p. 2)

Growing demand for care-work at home in the pre-digital era has been summarised as "institutionalised informalisation" (Strüver, 2013, p. 198) and is now known as the 
"formalisation of the informal economy" (Huws, 2019, p. 20) and as a platform-based formalisation which creates trust between strangers (Ticona \& Mateescu, 2018). Care platforms like peer-to-peer-business models aggregate data from the personal profiles of care workers with data related to their responsiveness and customer evaluations. This kind of algorithmic intensification of exploitation and surveillance is in stark contrast to the attributes, such as responsibility and trust, that characterise care relationships (Flanagan, 2019; van Doorn, 2017). Moreover, as part of the gig or on-demand economy, care platforms intensify the unequal power relations between the peers and encourage workers' flexibility in terms of when, where and what they work on and the expected income they receive for that work.

Current platform-mediated care-work challenges the classification of such work as unpaid, domestic women's work and seems to redefine the relations between value, visibility and vulnerability of care workers. Yet it does not contest the invisibility of care-work, its association with the private sphere, or the vulnerability that is typically associated with flexibility. On the contrary, we would rather suggest that the persistent invisibility and 'private-ness' of care-work intensifies its devaluation and the related precarity of workers, despite being paid work. For example, although the workers who do such labour do not know each other they are in a constant competition regarding wages, speed, rating results, and the overall quality of their gigs.

In a nutshell, it could be said that the invisibility of care-work and the interdependencies of gendered, racialised and classified inequality are a prerequisite for and intensified by platforms. At the same time, "code, social media, and data now play a central role in shaping gender and racial identities, reinforcing sexist and racist stereotypes" (Gieseking, 2019, p. 86). However, both the working bodies and the re/productive work done remain hidden and unseen. Furthermore, Ticona and Mateescu (2018, p. 4400) make a case that this invisibility also includes a disappearance behind the 'uberizationnarrative' regarding on-demand platforms that draw public and academic attention mainly to Airbnb, Uber and food platforms-not to the much bigger platforms such as care.com (see also Barns, 2020).

Just as in the pre-digital era, the seemingly everyday micropolitics of care-work are now, as a part of the on-demand platform economy, linked to macropolitical structures, such as neoliberal framings of labour, the gendered divisions of labour, and the feminisation, racialisation and precarity of care-work and related spatial politics (Strauss, 2019; see also Meehan \& Strauss, 2015). Its contribution in technocapitalism means that platform-mediated care-work, far from disrupting gendered social and spatial relations, tends rather than to call it into evidence as its manifestation: "Housework, it turns out, is at the epicentre of capitalism. And the labour of social reproduction, which underpins it, also represents its future potential for expansion. Feminist strategies for addressing it will therefore have to take on capitalism itself" (Huws, 2019, p. 21).

\section{Outlook and Research Gaps: Invisibilities and Inequalities}

In bringing together feminist digital geographies with critical urban studies in order to address the mutual construction of society and space by platform economies, we have highlighted how digital practices shape socio-spatial everyday praxes of different subjectivities. In particular, we have been attentive to gender norms as they become evident again in their relation to public and private spaces that are, in turn, reproduced by the platformisation of urban everyday life. The underlying technocapitalist structure of the platform economy and the social processes that are built upon it are shaped by subjectivities such as gender, race and class and platform urbanism thus does advance unequal power relations. Digital principles of standardisation, scope/scale and speed/volume mirror the foundational logics of this recent kind of capitalism (Elwood, 2020, p. 8). The spatial public-private divide is manifested in platform urbanism and can be discussed as a form of digital divide that relies on socio-spatial inequalities and reproduces gendered subjectivities at the same time. In this outlook, we therefore stress the role of space in sociotechnological change in terms of urban mobility and care-work platforms, which as effects of technocapitalism reproduce the invisibilities and inequalities along gender, race and class.

Platforms contribute to a gendered production of space. It became clear that car sharing does not break up gendered mobility patterns, but rather reinforces inequality structures, which we call a gendered platform mobility divide. On the demand side of the free floating car sharing platforms, it can be seen that these address an exclusive group of users, most of whom are male, young with above-average incomes. The algorithmgenerated services reinforce this homogeneous constellation. The need for mobility that allows frequent and longer stops along the journey is not provided with this mode of car sharing. However, route chains are a daily need of people who care for family members and for people adding several platform gigs throughout a day-and that might be more time-consuming and/or more expensive. These activities are mainly carried out by women who are dependent on other modes of mobility.

To date, the development of mobility and care platform infrastructures and services appears to be an exclusively urban phenomenon-one that, being concentrated in metropolitan centres, privileges already advantaged areas within cities. Although urban environments certainly derive benefit from the existing dense range of mobility services, the urgent infrastructural needs in rural and suburban areas are currently not being met by digitalisation and platform-mediated mobility and care services.

The current state of knowledge on the business models and modes of use of free floating car sharing plat- 
forms shows (Alonso-Almeida, 2019; Uteng \& Cresswell, 2008 ) that 1) the gendered division of labour in carework continues through digitised mobility practices in public spaces; 2 ) the service structure of free floating car sharing in terms of range, charging mode and vehicle facilities is neither adapted to the needs of family carework, nor to platform-mediated care-work; and 3) the promised flexibilisation of supply services and optimisation of urban infrastructures only apply to previously privileged population groups. We derive the following questions from these findings:

To what extent do car sharing platforms make a contribution to socially inclusive mobility in large European cities that is optimised in terms of costs, time and traffic?

Could car sharing platforms in suburban or rural areas, with low public transport coverage, cover a wider range of mobility needs, or are the supply structures in principle not geared to diverse needs?

Do private, public and non-commercially operated mobility platforms differ in their usability for route chains?

While care-work at home always has been beyond the formal workplace, digital technologies have enabled various modes of work to take place at home without substantially touching the established gendered division of labour. Departing from the essentialist stance equating care-work with women's work and shifting the focus to gendered power relations includes highlighting sociospatial inequalities, including the ongoing devaluation and invisibility of care-work on the one hand and the feminisation of poorly paid work on the other. We conclude from research on platform-mediated care-work in North America and Australia (Flanagan, 2019; Ticona \& Mateescu, 2018; van Doorn, 2017) that 1) the gendered division of public and private spaces is not only manifested by care platforms but is essential for their existence and that 2) the invisibility of care-work intensifies intersectional inequalities of race, gender and class and discrimination by platforms. Especially with concentration on care-work platforms, future research in European cities needs to centre on the following questions:

To what extent are care-work platforms urban phenomena relying on population density and heterogeneity, on short travel distances, anonymity etc. that change the use, perception and production of material urban space?

Do care platforms produce new spatialisations of the social? Or do they manifest pre-digital spatial divides and related uncertainties, inequalities and invisibilities?
As most of the research on urban care-work platforms stems from the USA and Australia: Are care platform effects the same in Europe?

Digital platforms mediate specific services for everyday life in cities, lead to new relations and interaction between service providers and users. The two examples of sectoral platforms (mobility and care) influence social relations and spatial productions in different ways. However, both generate standardisation and normalisation of everyday practices that create new socio-spatial exclusions or reinforce existing ones.

Problems of urban divides cannot be fixed by outsourcing public services to platforms. Their success models are disruption and network effects by size. This dynamic was, for example, very obvious during the 'lockdown' related to the Covid 19-pandemic: Neighbourhood platforms for the solidarity supply and sharing of goods, which had spontaneously emerged at the beginning of the pandemic, either vanished or were very quickly taken over by commercial platforms offering paid services due to network effects. Platform providers aim to grow and scale up their services to dominate the market. They are not interested in solving local and social problems.

Furthermore, platform economies take the diversity of urban population not into account, but consider their workers and their customers-and their needsas universal. The mobility patterns and needs of careworkers, for example are not taken up by the mobility platforms as they are more oriented towards recreational use and both socially and spatially address only selected parts of the urban population. However, combining the research on mobility and care-work platforms and following Leszczynski (2020), we should intensify the search for emancipative potentials through care and mobility platforms with focus on the gendered division of labour aiming for socio-spatial justice in platformoperated cities.

As feminist and critical urban geographies are concerned with people's everyday life and socio-spatial inequalities - that is, social inequalities related to the production of space and to spatial segregation resting on social structures and identities-the present technocapitalist production of urban space needs further empirical attention, especially in European cities. Technocapitalism is increasingly part of and regulating people's daily lives-and occurs again along norms based on gender, race and class. Linking care and mobility as two prominent urban platform economies allows us to put forward research on normative digital-socio-spatial relations particularly addressing inequalities inherent in these relations.

\section{Acknowledgments}

This text was produced with support from the ElisabethList-Fellowship-Programme for Gender Research of the 
University of Graz, the Europe-University Flensburg and ongoing discussions with the participating junior fellows Yannick Ecker, Marcella Rowek and Henk Wiechers.

\section{Conflict of Interests}

The authors declare no conflict of interests.

\section{References}

Alonso-Almeida, M. (2019). Carsharing: Another gender issue? Drivers of carsharing usage among women and relationship to perceived value. Travel Behaviour and Society, 17, 36-45.

Attoh, K., Wells, K., \& Cullen, D. (2019). “We're building their data": Labor, alienation, and idiocy in the smart city. Environment and Planning D: Society and Space, 37(6), 1007-1024.

Barns, S. (2019). Negotiating the platform pivot: From participatory digital ecosystems to infrastructures of everyday life. Geography Compass, 13(9), 1-13.

Barns, S. (2020). Platform urbanism. Singapore: Springer. Bauriedl, S., \& Strüver, A. (2018). Smart City: Kritische Perspektiven auf die Digitalisierung in Städten [Smart City: Critical perspectives on the digitisation of cities]. Bielefeld: Transcript.

Beebeejaun, Y. (2017). Gender, urban space, and the right to everyday life. Journal of Urban Affairs, 39(3), 323-334.

Bondi, L. (1998). Gender, class, and urban space: Public and private space in contemporary urban landscapes. Urban Geography, 19(2), 160-185.

Bondi, L., \& Rose, D. (2003). Constructing gender, constructing the urban: A review of Anglo-American feminist urban geography. Gender, Place and Culture, 10, 229-245.

Brickell, K. (2012). 'Mapping' and 'doing' critical geographies of home. Progress in Human Geography, 36(2), 225-244.

Dyck, I. (2005). Feminist geography, the 'everyday,' and local-global relations: Hidden spaces of place-making. The Canadian Geographer, 49(3), 233-243.

Elwood, S. (2020). Digital geographies, feminist relationality, Black and queer code studies: Thriving otherwise. Progress in Human Geography. https://doi.org/ 10.1177/0309132519899733

Elwood, S., \& Leszczynski, A. (2018). Feminist digital geographies. Gender, Place \& Culture, 25(5), 629-644.

European Commission. (2020). European innovation partnership on smart cities and communities. Brussels: European Commission. Retrieved from https:// ec.europa.eu/info/eu-regional-and-urbandevelopment/topics/cities-and-urbandevelopment/city-initiatives/smart-cities_en

Federici, S. (2019). From crisis to commons: Reproductive work, affective labor and technology, and the transformation of everyday life. In S. Federici (Ed.), Re-enchanting the world (pp. 175-187). Oakland, CA:
PM Press.

Flanagan, F. (2019). Theorising the gig economy and home-based service work. Journal of Industrial Relations, 61(1), 57-78.

Gieseking, J. J. (2019). Digital. In Antipode Editorial Collective (Ed.), Keywords in radical geography (pp. 85-89). Oxford: Blackwell.

Giesel, F., \& Nobis, C. (2016). The impact of carsharing on car ownership in German cities. Transportation Research Procedia, 19, 215-224.

Gilbert, M. (2010). Theorizing digital and urban inequalities. Information, Communication \& Society, 13(7), 1000-1018.

Graham, M. (2020). Regulate, replicate, and resist: The conjunctural geographies of platform urbanism. Urban Geography. https://doi.org/10.1080/ 02723638.2020 .1717028

Graham, S. (2002). Bridging urban digital divides? Urban polarisation and Information and Communications Technologies (ICTs). Urban Studies, 39(1), 33-56.

Hanson, S. (2010). Gender and mobility: New approaches for informing sustainability. Gender, Place and Culture, 17(1), 5-23.

Hayden, D. (1983). The grand domestic revolution: A history of feminist designs for American homes, neighborhoods, and cities. Cambridge, MA: MIT Press.

Hunt, A., \& Machingura, F. (2016). A good gig? The rise of on-demand domestic care: Development progress (Working Paper No. 07). London: Overseas Development Institute. Retrieved from https://www.odi.org/sites/odi.org.uk/files/resourcedocuments/11155.pdf

Huws, U. (2019). The hassle of housework: Digitalization and the commodification of domestic labour. Feminist Review, 123(1), 8-23.

Kitchin, R. (2014). The real-time city? Big data and smart urbanism. GeoJournal, 79, 1-14.

Kitchin, R. (2015). Making sense of smart cities. Addressing present shortcomings. Cambridge Journal of Regions, Economy and Society, 8(1), 131-136.

Kong, L., \& Woods, O. (2018). Smart eldercare in Singapore. Journal of Aging Studies, 47, 1-9.

Law, R. (1999). Beyond 'women and transport': Towards new geographies of gender and daily mobility. Progress in Human Geography, 23(4), 567-588.

Lee, A., Mackenzie, A., Smith, G. J. D., \& Box, P. (2020). Mapping platform urbanism: Charting the nuance of the platform pivot. Urban Planning, 5(1), 116-128.

Leszczynski, A. (2020). Glitchy vignettes of platform urbanism. Environment and Planning D: Society and Space, 38(2), 189-208.

Liyanage, S., Dia, H., Abduljabbar, R., \& Bagloee, S. (2019). Flexible mobility on-demand: An environmental scan. Sustainability, 11(5), 1-39.

Lucas, K. (2012). Transport and social exclusion: Where are we now? Transport Policy, 20, 105-113.

Massey, D. (1994). Space, place and gender. Minneapolis, MN: Minnesota University Press. 
Massey, D. (2005). For space. London: Sage.

Meehan, K., \& Strauss, K. (2015). Precarious worlds: Contested geographies of social reproduction. Athens: University of Georgia Press.

Parker, B. (2011). Material matters: Gender and the city. Geography Compass, 5(6), 433-447.

Peake, L. (2016). The twenty-first century quest for feminism and the global urban. International Journal of Urban and Regional Research, 40(1), 219-227.

Prettenthaler, F. E., \& Steininger, K. W. (1999). From ownership to service use lifestyle: The potential of car sharing. Ecological Economics, 28, 443-453.

Richardson, L. (2018). Feminist geographies of digital work. Progress in Human Geography, 42(2), 244-263.

Richardson, L. (2020). Coordinating the city: Platforms as flexible spatial arrangements. Urban Geography, 41(3), 458-461.

Sadowski, J. (2020). Cyberspace and cityscapes: On the emergence of platform urbanism. Urban Geography. https://doi.org/10.1080/02723638.2020.1721055

Scholten, C. L., \& Joelsson, T. (2019). Integrating gender into transport planning. Cham: Palgrave.

ShareNow GmbH. (2020). Über ShareNow [About ShareNow]. ShareNow $\mathrm{GmbH}$. Retrieved from https://www.share-now.com/de/de/faq/aboutshare-now

Sheller, M. (2012). Sustainable mobility and mobility justice: Towards a twin transition. In J. Urry \& M. Grieco (Eds.), Mobilities: New perspectives on transport and society (pp. 289-304). Farnham and Burlington, VT: Taylor and Francis.

Singh, Y. J. (2019). Is smart mobility also gender-smart? Journal of Gender Studies. https://doi.org/10.1080/ 09589236.2019.1650728

Srnicek, N. (2016). Platform capitalism. Cambridge, MA: Polity Press.

Strauss, K. (2019). Labour geography III: Precarity, racial capitalisms and infrastructure. Progress in Human Geography. https://doi.org/10.1177/030913

\section{8}

Strauss, K., \& Xu, F. (2018). At the intersection of urban and care policy: The invisibility of eldercare workers in the global city. Critical Sociology, 44(7/8), 1163-1178.

Strüver, A. (2013). "Ich war lange illegal hier, aber jetzt hat mich die Grenze übertreten": Subjektivierungsprozesse transnational mobiler Haushaltshilfen ["I was in the country illegally for a long time, but now the border has surpassed me": Processes of subjectivisation of transnationally mobile domestic helps]. Geographica Helvetica, 68(3), 191-200.

Strüver, A., \& Bauriedl, S. (2020). Smart city narratives and narrating smart urbanism. In M. Kindermann \& R. Rohleder (Eds.), Exploring the spatiality of the city across cultural texts: Narrating spaces, reading urbanity (pp. 185-204). Cham: Palgrave.

Swyngedouw, E., \& Kaika, M. (2014). Urban political ecology. great promises, deadlock...and new beginnings? Documents d'Anàlisi Geogràfica, 60(3), 459-481.

Ticona, J., \& Mateescu, A. (2018). Trusted strangers: Care platforms' cultural entrepreneurship in the ondemand economy. New Media \& Society, 20(11), 4384-4404.

Uteng, T. P., \& Cresswell, T. (Eds.). (2008). Gendered mobilities. Aldershot: Ashgate.

van Dijck, J., Poell, T., \& De Waal, M. (2018). The platform society: Public values in a connective world. Oxford: Oxford University Press.

van Doorn, N. (2017). Platform labor: On the gendered and racialized exploitation of low-income service work in the 'on-demand' economy. Information, Communication \& Society, 20(6), 898-914.

Wigley, E., \& Rose, G. (2020). Who's behind the wheel? Visioning the future users and urban contexts of connected and autonomous vehicle technologies. Geografiska Annaler B, 102(2), 155-171.

Wiig, A. (2016). The empty rhetoric of the smart city: From digital inclusion to economic promotion in Philadelphia. Urban Geography, 37(4), 535-553.

\section{About the Authors}

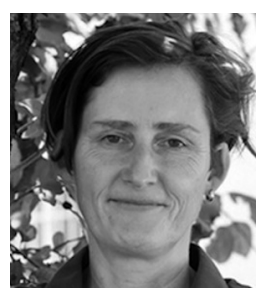

Sybille Bauriedl is Professor of Integrative Geography at the Europe-University Flensburg (Germany). She has been researching and teaching sustainable urban development and global environmental conflicts since the 1990s. She is engaged in scientific networks of political ecology and feminist geography and is involved in the right to the city movement. Current research projects deal with local energy transition, smart urbanism, colonial infrastructure in European port cities, and climate justice.

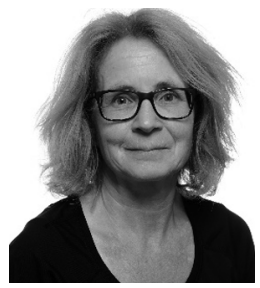

Anke Strüver is Professor of Human Geography with a focus on Urban Studies at the University of Graz (Austria) since Fall 2018. In 2004 she completed her PhD at the University of Nijmegen on the socio-cultural production of cross-border spaces and their effects on everyday practices. She became a Professor of Social Geography at the University of Hamburg in 2010. Her research focuses on embodied human-environment relations in the city, especially along the themes of health, food and active mobility, as well as focused on digitalisation and sustainable co-laboration. 